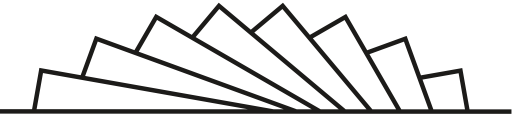

\title{
CONSTITUCIONALLZZCLIÓN deL deRECHO PENAL EN COLOMBia debioO PROCESO Y CLÁUSULA DE EXCLUSIÓN
}

\section{CONSTITUTIONALIZATION OF CRIMINAL LAW IN COLOMBIA DUE PROCESS AND \\ EXCLUSION CLAUSE}

\section{RESUMEN}

\begin{abstract}
Motiva este artículo, la reflexión crítica constructiva al proceso de constitucionalización del derecho penal, manifestado a partir de garantías superiores que materializan principios positivados en la Constitución Política de Colombia y su desarrollo legislativo a partir del ordenamiento penal y procesal penal; fenómeno jurídico filosófico que defiende la indemnidad de los derechos fundamentales, entre los cuales la cláusula de exclusión es una manifestación del debido proceso.
\end{abstract}

Palabras Clave: Constitución Política de Colombia, Debido Proceso, Cláusula de exclusión, Derechos Humanos, Garantías constitucionales, Estado Social de Derecho, Sistema penal acusatorio

\section{JOSÉ MEJÍA MEJÍA ${ }^{1}$}

${ }^{1}$ Artículo de revisión, José Mejía Mejía, Abogado de la Universidad de Boyacá; Especialista en Derecho Disciplinario de la Universidad Externado de Colombia; Especialista en Derecho Penal y Procesal Penal de la Universidad Santo Tomás; MagÍster en Derecho Penal y Procesal Penal de la Universidad Santo Tomás. Ex - servidor público (Profesional Universitario) de la PGN; ex - funcionario (Fiscal local/ seccional) de la FGN; ex Juez Civil del Circuito. Actualmente Juez Promiscuo; catedrático de la Universidad de Boyacá; doctorando en Derecho de la Universidad de Baja California, Tepic, Nayarit, México. 


\section{ABSTRACT}

Citar este artículo así:

Mejía Mejía, J. (2021). Constitucionalización del derecho penal en colombia, debido proceso y cláusula de exclusión. Justicia, sociedad y derecho, 122-136.

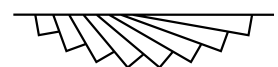

Motivates this article, the constructive critical reflection to the process of constitutionalization of criminal law, manifested from superior guarantees that materialize positive principles in the Political Constitution of Colombia and its legislative development from the criminal and criminal procedure; philosophical legal phenomenon that defends the indemnity of fundamental rights, among which the exclusion clause is a manifestation due process.

Keywords: Political Constitution of Colombia, Due Process, Exclusion Clause, Human Rights, Constitutional Guarantees, Social State of Law, Accusatory Criminal System 


\section{INTRODUCCIÓN}

Este artículo expondrá una perspectiva filosófica constitucional sobre el proceso de constitucionalización del derecho penal y procesal penal colombiano, fenómeno jurídico político y filosófico, que enfrenta dos posturas, a saber: una que defiende el garantismo procesal penal, a partir de garantías constitucionales y el respeto de los derechos fundamentales estructuradores de la dignidad humana principio y fin del estado social y democrático de derecho y otra, que propugna por investigar y juzgar las conductas delictuales y de ser necesario, so pretexto de combatir la criminalidad y llegar a la verdad real, pretermitir el respeto a las formas propias de cada juicio, tesis sustentada sobre un sesgado principio de legalidad.

El proceso de constitucionalización del derecho penal, que no es distinto a observar el ordenamiento jurídico penal y procesal penal, de manera holística, no solamente desde la inclusión de principios orientadores contenidos tanto del estatuto sustantivo, como en el procesal, sino observar diligentemente los derechos fundamentales y garantías constitucionales que por vía de principios positivados en el ordenamiento penal, que avalan remedios procesales a los vicios probatorios, bien por nulidad, ora por ilicitud, mediante instituciones jurídicas como la cláusula de exclusión, acepción del debido proceso y por demás, norma de carácter iusfundamental que obliga al estudio de las corrientes filosóficas que inspiran la permeabilización constitucional del derecho procesal penal colombiano. En consecuencia, en el artículo que se presenta, se observará la traza de los derechos fundamentales involucrados, expresión político filosófica del estado social y democrático de derecho, con alcance jurídico y contenido axiológico desde la teoría filosófica de Dworkin (1977) y el contenido de principios desde cláusula "principia iuris et de iuris", de la teoría de Ferrajoli (2016).

Se proseguirá con un atisbo a preceptos constitucionales con contenidos puros de derechos humanos contendidos no solamente en el texto de la constitución sino en, (i) instrumentos internacionales de derechos humanos e incorporados a la constitución vía de bloque constitucionalidad y, (ii) decisiones de tribunales internacionales de protección de derechos humanos y fundamentales, pero sin desorientar el objeto de estudio, que pretende focalizar la actividad probatoria revestida de garantías constitucionales, dentro del proceso penal colombiano.

Finalmente, se destacarán aspectos constitucionales de la estructura probatoria del proceso penal en Colombia, extractando lo pertinente del artículo 29 superior, precepto de derecho fundamental, del que se analizarán, acepciones relativas a la actividad probatoria en el transcurrir de la actuación procesal penal.

Afianza esta postura que entiende y propugna por observar las garantías constitucionales, la precisión de las normas de carácter constitucional, legal y supranacional, así como la citación de decisiones de Tribunales Internacionales, en actuaciones violatorias de derechos fundamentales y constitucionales, por irregularidades tanto en la aducción como en la valoración de elementos de convicción viciados por ilicitud o ilegalidad. 


\section{METODOLOGÍA}

La investigación es de tipo teórica jurídica, por cuanto está sustentada desde una visión elaborada, a partir del procesamiento del pensamiento abstracto, que se condensa en constructos, teoremas, conceptos, leyes, o teorías, en consecuencias, este artículo parte del análisis de posturas o tesis defendidas tanto por doctrinantes nacionales, Uprimny, Urbano, Daza, Carrasquilla, Gómez, entre otros; así como connotados autores del derecho, obsérvese, Bobbio, Ferrajoli, Alexy, Dowrkin. El método de investigación, del que es resultado el artículo que se presenta a la comunidad jurídica lleva implícito la propuesta de construcción de una dogmática axiológica positiva, a partir de premisas de derechos humanos con incidencia en proceso de constitucionalización del derecho penal.

\section{PERSPECTIVA FILOSÓFICA}

Es imperioso comenzar este artículo, reflexionando sobre el estudio de los derechos fundamentales desde la filosofía político jurídica, como ciencia que sustenta la legitimidad de los sistemas jurídicos ínsitos en el modelo de estado social y democrático de derecho como esencia de revelación del ordenamiento jurídico, particularmente en la jurisdicción penal desde donde, como prerrequisito de política criminal es perentorio garantizar que por vía de positivización se morigere la tensión entre los derechos fundamentales y el esclarecimiento de los hechos en el proceso penal.

Así, se advierte tanto del sistema jurídico colombiano, como de los más recientes ordenamientos que son producto de las nuevas constituciones y estas a su vez producto de la incorporación de principios como respuesta a la crisis del positivismo con raigambre en el escepticismo ético, esto es, la creencia de que no existen juicios morales objetivamente verdaderos, universalmente válidos y eternos (Bonorino, 2008). Desde esta óptica el positivismo venía siendo entendido como una posición jurídico - filosófica que defiende el concepto de derecho extirpando de su concepto cualquier injerencia de la moral, en cuanto parte del postulado fundamental, según el cual, la ciencia es el único criterio de verdad y si el derecho es ciencia, el positivismo jurídico habría de entenderse como teoría científica, y a esta no puede presuponerse en su conocimiento y descripción del derecho positivo la existencia de una fuente trascendente del derecho (Kelsen, 2008).

Superado el apego a la concepción filosófica del positivismo jurídico, se admite la coexistencia de postulados del iuspositivismo y el iusnaturalismo, en concepción teórica de Dowrkin (1977) construida sobre una teoría moral que no excluya ni el razonamiento moral ni el razonamiento filosófico, recuérdese como Bobbio (1982), desde una perspectiva eminentemente positivista consideró imposible construir una fundamentación de los derechos humanos sin caer en una alusión iusnaturlistica a partir de concepciones filosóficas como naturaleza humana, persona moral y ley natural.

En consecuencia, la incorporación de normas de derecho fundamental como principios positivados se traducen en auténticas garantías, verbigracia, al debido proceso del cual es una acepción, la sanción mediante la exclusión de las pruebas obtenidas de manera ilícita 
o ilegal, son finalmente, criterios de coherencia con el desarrollo de los derechos humanos, por tanto debemos hacer una aproximación a estas relaciones, es decir, tanto a los derechos humanos como los derechos fundamentales contenidos en la constitución y entendidos de Roxin, citado por Armijo para quien el sistema procesal, es el reflejo del régimen político ideológico y el sistema probatorio es la comuna vertebral del sistema procesal Armijo (1997); para entender el proceso de reconocimiento de los derechos humanos debe partir de aceptar la metamorfosis que han experimentado las constituciones más actuales, comenzando por entender su primordial y preponderante ubicación en los nuevos estados sociales y democráticos de derecho, posteriores a los estados liberales de derecho, según se concibe de la teoría garantista desde la cual comienza el análisis normativo dentro del contexto de la dogmática jurídica y la teoría del derecho.

Y es que a propósito de la dogmática a que alude la constitucionalización del derecho, es menester entenderla desde la perspectiva de la dogmática axiológica positiva, que enseña Carrasquilla, para quien, esta debe incorporar además premisas y conceptos fundamentales de los derechos humanos y los derechos fundamentales, en tanto, todo concepto de un derecho penal liberal y democrático que quiera pretender en serio el respeto de los derechos humanos tiene que comenzar porque cada concepto que emplee y cada paso metodológico que emprenda esté permeado por las valoraciones esenciales de los derechos internacionales y los derechos fundamentales de la constitución positiva (Carrasquilla, 2014).

Así pues, el estudio de los derechos fundamentales preservadores del debido proceso penal, se observa desde la teoría que explica Ferrajoli (2016), para quien éstos se vislumbran desde principios que se pueden llamar principia iuris et de iuris, pero no restrictivamente in iuri, por cuanto hacen parte del ordenamiento, no obstante internos o externos al derecho positivo, es decir, se insinúan, no se formulan; tal como sucede en derechos que incorporan instituciones jurídico penales y procesales penales como el principio de legalidad estricta, el de separación de poderes, el conjunto de garantías penales y procesales, los cuales, enseña el mismo autor, pese a ser más o menos explícitos en las normas de derecho positivo, dogmáticamente deben interpretarse en el contexto de otras normas del derecho positivo del que forman parte, postura que honra el ordenamiento interno penal colombiano al conciliar por vía de bloque de constitucionalidad imperativos de los sistemas globales y regionales de protección de los derechos humanos, derecho internacional humanitario, derecho internacional de los derechos humanos, así como del sistema interamericano de derechos humanos. No obstante, es oportuno aclarar que cuando hablamos de derechos humanos no nos referimos a la naturaleza de ningún sistema jurídico en específico, nos referimos a esa constante que aparece codificada en los sistemas filosóficos como naturaleza humana.

\section{LOS DERECHOS HUMANOS Y LA PRIMACÍA DE DERECHOS FUNDAMENTALES EN EL ORDENAMIENTO PENAL COLOMBIANO}

Viene oportuno acercarnos a la relación que existe entre derechos fundamentales de una parte, recuérdese, nos concita la regla de exclusión como derecho 
fundamental contenido en el artículo 29 superior y, de otra parte, las garantías constitucionales, toda vez que el derecho fundamental en mención, llevado al procedimiento penal es un principio rector de la actuación jurisdiccional en la acepción iuspunitiva, imperativo según el cual, toda prueba obtenida con violación de las garantías fundamentales será nula de pleno derecho, por lo que deberá excluirse de la actuación procesal (Código de Procedimiento Penal, 2014). Para precisar las relaciones entre derechos fundamentales y garantías constitucionales, siguiendo a Ferrajoli (2016), los derechos fundamentales se definen como derechos universales, es decir conferidos a todos por normas jurídicas $y$, derechos subjetivos como expectativas que corresponden a una obligación o una prohibición; en consecuencia, la implicación entre derechos y garantías no es de tipo asertivo sino de tipo normativo.

Señálese como, por virtud del artículo 93 de la Constitución Política de Colombia, los tratados y convenios internacionales ratificados por el Congreso, que reconocen los derechos humanos y que prohiben su limitación en los estados de excepción, prevalecen en el orden interno y, los derechos y deberes consagrados en la Carta, se interpretarán de conformidad con los tratados internacionales sobre derechos humanos ratificados por Colombia (Constitución política de Colombia, 1991).

En virtud del anterior precepto constitucional y en pacífico entendimiento que la Constitución es norma de normas (Carrasquilla, 2014), la legislación penal interna, tanto sustantiva como procesal, debe acatar los tratados y convenios internacionales debidamente ratificados que amparan derechos humanos, respetándolos con el valor prevalente de la constitución e interpretando los derechos y los deberes constitucionales y legales, sustantivos y procedimentales, conforme a los mencionados tratados.

Necesario es señalar, cómo la Constitución Política Colombiana, carta de 1991, imprime fuerza vinculante a los derechos humanos en el ordenamiento jurídico colombiano, así es la enseñanza y la exigencia funcional, atribuida por el Consejo Superior de la Judicatura, a través de la Escuela Judicial Rodrigo Lara Bonilla, al señalar que, los contenidos normativos propios de los derechos humanos son derecho obligatorio supranacional, $y$ en general constitucional, que debe ser aplicado por los funcionarios judiciales, incluidos los jueces, y respetado por los particulares (Upriminy, Uprimny, \& Parra, 2008).

Entendido así, el contenido del artículo 29 superior, y acentuando el contenido del quinto inciso del precepto en cita, es nula, de pleno derecho, la prueba obtenida con violación del debido proceso (Constitución Política de Colombia, 1991) en consecuencia, aplicar la cláusula de exclusión es respetar con preponderancia constitucional los tratados y convenios sobre derechos humanos, que fueron fuente de inspiración del constituyente para incorporarlos al ordenamiento interno y que obliga a que de manera somera se mencionen algunos, así:

Ley 16 de 1972. En su artículo 11 "Protección de la Honra y de la Dignidad". Señala: "1) Toda persona tiene derecho al respeto de su honra y al reconocimiento de su dignidad. 2) Nadie puede ser objeto de injerencias arbitrarias o abusivas en su vida privada, en la de 
su familia, en su domicilio o en su correspondencia, ni de ataques ilegales a su honra o reputación. 3) Toda persona tiene derecho a la protección de la ley contra esas injerencias o esos ataques" (Congreso de Colombia, 1972).

Continuando con tratados que hacen parte del bloque de constitucionalidad, obliga observar y acatar a la Declaración Universal de los derechos Humanos, que en su Artículo 5 Indica: Nadie será sometido a torturas ni a penas o tratos crueles, inhumanos o degradantes; y en el Artículo 8 "Toda persona tiene derecho a un recurso efectivo, ante los tribunales nacionales competentes, que la ampare contra actos que violen sus derechos fundamentales reconocidos por la constitución o por la ley" (Asamblea General de la ONU, 1948).

En igual sentido la Ley 70 de 1986, Por medio de la cual se aprueba la Convención contra la tortura y otros tratos o penas crueles, inhumanos o degradantes", adoptada en Naciones Unidas el 10 de diciembre de 1984 plantea que por tortura se entiende todo acto por el cual se inflija intencionadamente a una persona dolores o sufrimientos graves, ya sean físicos o mentales, con el fin de obtener de ella o de una tercera información o una confesión (Congreso de Colombia,1986).

Como observa, del plexo de normas supranacionales, que por vía de bloque de constitucionalidad son parte de nuestra constitución, todas proscriben cualquier acto violatorio de los derechos humanos o del derecho internacional humanitario, cuando garantizan su respeto, las cuales en nuestro ordenamiento interno son garantía de los derechos fundamentales, por tanto, estos son la fundamentación es una expresión iusfilósifica que incorpora principios y valores en un sistema jurídico permeado por la ciencia del derecho constitucional con raigambre en el reconocimiento y subordinación de los derechos humanos, preceptos universalmente válidos que enseñan cómo, mediante la positivización de derechos se incorporan cláusulas con contenido en realidades codificadas en un sistema constitucional, conclúyase así, como lo enseña Pérez (2013), "la cuestión de los derechos fundamentales es un tema de derecho positivo en tanto que se refiere a la manera en la que tales principios aparecen expresados en el contrato fundante de una sociedad política o Nación determinada".

Pacífica es la teoría según la cual el florecimiento de los derechos fundamentales como máxima expresión de las constituciones contemporáneas, es la más pura aceptación de un nuevo contrato social democrático y pluralista pero alineado con el irrestricto respeto a los derechos humanos, entendidos por el precitado tratadista como manifestaciones o concepciones de los derechos fundamentales que deben su existencia a la metafísica de los derechos o, lo que es lo mismo, se debe a la existencia de diferentes concepciones del mundo que organiza valores y principios jurídicos de manera autónoma en sus sistemas constitucionales.

Es necesario focalizar la atención en el respeto de los derechos fundamentales y de los derechos humanos de manera concreta y para los fines de este artículo, en el desarrollo del proceso penal, por tanto, 
al estudiar los límites que imponen al derecho penal, como expresión del proceso de constitucionalización del derecho, debemos acercarnos al apotegma de la dogmática axiológica positiva, a cuyos conceptos fundamentales y premisas tienen que haberse incorporado ya los derechos humanos y los derechos fundamentales (Fernández, 2014).

Partiendo de la anterior premisa, en un primer acercamiento al objeto de estudio, es acentuar como imperativo la obligación impuesta desde la corriente filosófica de los derechos humanos, la obligación de revestir de todas las garantías, propias del debido proceso, como norma iusfundamental, todo el proceso penal, pero de manera muy concreta la actividad probatoria, privilegiando el concepto de derecho penal liberal y democrático que enseña que el respeto de los derechos humanos principia con permear cada paso, cada etapa del proceso por las valoraciones esenciales de los derechos humanos internacionales y de los derechos fundamentales de la constitución (Fernández, 2014).

Valga acentuar cómo la sociedad política ha decidido proteger ciertos valores y principios que considera imprescindibles para el desarrollo de la vida social, incorporándolos en la Constitución, como el más idóneo mecanismo para proteger a los individuos del mismo estado, que no es otra cosa que una construcción social, que ha surgido precisamente de la necesidad de ofrecer garantías a una serie de derechos-libertades sustanciales. Toda constitución moderna, escrita o no, supone, prevalentemente, derechos fundamentales anteriores a la formación del estado, la necesidad y los mecanismos de protección, cuya tarea es la vigilancia de los derechos constitucionales (Pérez, 2013), entre los cuales se consideran en el derecho penal constitucionalizado de Colombia, la inclusión del debido proceso y como mecanismo de protección, la cláusula de exclusión probatoria, y la norma superior delega su protección a un sistema autoritario central, el Estado, que se encarga a partir del desarrollo legislativo, de gestionar la dinámica mediante el monopolio legítimo, en nuestro objeto de estudio, el procedimiento penal.

Al estudiar de manera sistémica y concordante la cláusula de exclusión, se reitera, como una acepción del derecho fundamental del debido proceso, debemos ubicarla no solamente, dentro de esta órbita del derecho positivo interno o dentro del contexto de los derechos humanos sino, principalmente como la más cara expresión del principio Pro Homine, que restringe el poder punitivo del estado e impide utilizar los derechos en desfavor de los imputados, acusados o enjuiciados en un proceso penal.

Como se planteó, entender la efectivización de los derechos humanos y los derechos fundamentales es, al interior del ordenamiento jurídico, o al menos en el ordenamiento interno colombiano, un proceso de constitucionalización, es decir positivismo jurídico, valga entender de reglas y principios, tal vez incorporando pilares de la filosofía del derecho, contenidos en las teorías expuestas por Luigi Ferrajoli, que explica Pino (citado por Ferrajoli, 2016), a saber i) Una filosofía del Estado Constitucional, entre el derecho y política, ii) La superioridad de la Constitución y iii) 
Validez formal, validez sustancial y separación entre el derecho y la moral. Expone Ferrajoli, La democrazia attravarerso i diritti, (la democracia a través de los derechos, continúa en la constitución de una teoría del derecho y la democracia para el Estado constitucional -un ordenamiento jurídico dotado de Constitución rígida que codifica un catálogo de derechos y principio fundamentales (Ferrajoli, 2016). Así, la positivización de los derechos fundamentales y concretamente el debido proceso, en la constitución política de Colombia, es cuando menos la concreción en un catálogo de tales derechos y principios y se traduce en una clara limitación al poder del estado, concretamente al poder judicial que advierte una limitación al arbitrio de la interpretación y de la actuación procesal, es en concreto, un imperativo de sujeción al principio de estricta legalidad.

Vistas así las cosas, en el proceso penal propio de un estado social y democrático de derecho, en el ejercicio del derecho penal, los funcionarios judiciales, en quienes el Estado delega el monopolio legítimo de la violencia - ius puniendi - que está en cabeza del mismo Estado, no solamente declaran el derecho, sino que, realizan principios propios del modelo de estado constitucional que gravita en torno a la dignidad de las personas como razón de ser de este contrato social, develando así las potencialidades de un Estado Constitucional.

Centrando la atención en el proceso de constitucionalización del derecho penal al interior del ordenamiento interno colombiano, apremia centrar la atención no solamente en el modelo de estado que impera a partir de la constitución de 1991, sino en las normas que explicitan rasgos del modelo constitucional.

La Constitución Política de Colombia (1991), describe a la organización política de la Nación, como un Estado Social y Democrático de Derecho, por tanto es aceptada a partir del Estado de Derecho o liberal, el concepto de derechos, de legalidad, de límites a la arbitrariedad y la cláusula general omnímoda, según la cual la Constitución es norma de normas, en consecuencia, cimienta el Estado Colombiano, como lo señala Daza, más allá de definirse como un Estado que da preponderancia al establecimiento jurídico, se convierte en un Estado que se preocupa por garantizar a todos sus integrantes una vida digna (Daza, 2015).

Acentúese, que el Estado Social de derecho, que propuso el Constituyente colombiano en 1991, mutó del Estado - represor de Derecho - a un Estado garantista del sujeto en donde el ordenamiento penal, ya constitucionalizado, es determinante en el respeto de los derechos, por contener límites reguladores del poder punitivo del Estado, que impidan la afectación a los bienes jurídicos que se tutelan, con preeminencia de la dignidad, principio y fin de nuestra Constitución, como lo afirma Gómez:

Para que la justicia sea el sustento de la democracia, el derecho penal, en un Estado Democrático de Derecho debe cumplir una de las más importantes funciones que tiene encomendada la actividad jurídica, en general en un Estado de Derecho: Garantizar los derechos fundamentales del individuo frente al poder arbitrario del Estado (Gómez, 2010). 
Pero para esto debe partirse en el derecho penal, que involucra tanto el sustancial como el procedimiental, desde la exigencia del modelo de Estado Democrático de Derecho.

\section{ASPECTOS CONSTITUCIONALES EN LA ESTRUCTURA PROBATORIA DEL PROCESO PENAL}

Conviene ahora puntualizar aspectos de la estructura probatoria del derecho penal en el constitucionalismo colombiano, el cual incorpora la cláusula de exclusión probatoria, norma que se ubica en la descripción del derecho fundamental al debido proceso como lo plantea la Constitución Política de Colombia (1991, art. 29):

"El debido proceso se aplicará a toda clase de actuaciones judiciales y administrativas. Nadie podrá ser juzgado sino conforme a leyes preexistentes al acto que se le imputa, ante juez o tribunal competente y con observancia de la plenitud de las formas propias de cada juicio. En materia penal, la ley permisiva o favorable, aun cuando sea posterior, se aplicará de preferencia a la restrictiva o desfavorable. Toda persona se presume inocente mientras no se la haya declarado judicialmente culpable. Quien sea sindicado tiene derecho a la defensa y a la asistencia de un abogado escogido por él, o de oficio, durante la investigación y el juzgamiento; a un debido proceso público sin dilaciones injustificadas; a presentar pruebas y a controvertir las que se alleguen en su contra; a impugnar la sentencia condenatoria, y a no ser juzgado dos veces por el mismo hecho. Es nula, de pleno derecho, la prueba obtenida con violación del debido proceso"

Comenzando por remembrar el concepto derecho fundamental que identifica la teoría de los derechos defendida por Alexy (1993), para quien los derechos fundamentales son solo aquellos derechos que pertenecen al fundamento mismo del Estado y que, por la tanto, son reconocidos en la constitución.

Como se advirtió párrafos antes, los derechos fundamentales en el ordenamiento interno están comprendidos en la Constitución Política de Colombia de 1991, de la cual, en virtud del artículo 93, hace parte el bloque de constitucionalidad, por tanto se acepta como fundamentación de la norma de derecho fundamental, los precitados criterios materiales / estructurales y se concreta, siguiendo a Urbano (2014), que en el régimen probatorio de la jurisdicción penal colombiana, se sustenta en tres instituciones, a saber: i) La reserva judicial de las libertades públicas, ii) la estructura básica del proceso penal y iii) el núcleo probatorio que hace parte de la estructura básica.

Centrando nuestra atención únicamente en la Constitución de 1991, y destacando las instituciones que relieva el autor, se verifica que de la reserva de las libertades públicas algunas manifestaciones están contenidas en los artículos 15, 28 y 32 que condiciona la injerencia del Estado al respeto de la inviolabilidad de la correspondencia, la libertad de locomoción y la exigencia de un orden judicial previo o un estado de flagrancia para su excepcional afectación, condiciones que denotan el respeto a los derechos fundamentales y el reconocimiento de la positivización de dichas facultades materializando así la rigidez de la constitución conforme lo observamos con Ferrajoli (2016). 
El proceso de constitucionalización del derecho penal en Colombia, fue más allá y en el mismo cuerpo de la constitución, fijó la estructura del proceso penal, como se lee en los preceptos 116, 235 y 250 superiores, radicando en la Fiscalía General de la Nación las funciones constitucionales de persecución, acusación y renuncia como excepción al principio de legalidad de la acción penal.

No obstante, pese a que la constitución política, es tímida en la estructura básica del proceso, en cuanto a la estructura probatoria, como lo advierte Urbano (2014), incluyó preceptos probatorios con valiosos contenidos tales como la reserva judicial de los derechos a la intimidad y a la libertad de locomoción, la regla de exclusión de la prueba ilícita y la exoneración del deber de declarar previstos en los artículos 15, 28, 29 y 34 (sic) 33 de la Constitución Política de Colombia.

Reitérese las referidas normas que son de índole constitucional, las cuales estructuran el plexo de garantías que deben observarse, en concordancia y en rigor con instrumentos internacionales, que se insiste, en virtud del bloque de condicionalidad, son parte integrante de nuestro ordenamiento penal y de obligatoria observancia, tanto en el derecho penal sustancial, como el procedimiento. Así, instrumentos internacionales como: Ley 70 de 1986, por medio de la cual se aprueba la Convención contra la Tortura y otros Tratos o Penas Crueles, Inhumanas o Degradantes, art. 1, según el cual se entenderá por el término tortura "todo acto por el cual se inflija intencionadamente a una persona dolores o sufrimientos graves, ya sean fisicos o mentales, con el fin de obtener de ella o de un tercero información o una confesión..."
(Convención contra la Tortura y otros Tratos Crueles, Inhumanos o Degradantes, 1986). A propósito de la regla de exclusión, manifestación de los derechos fundamentales garantí pueda ser invocada as constitucionales, La misma norma supranacional, en su artículo 15, es categórica: "Todo Estado Parte se comprometerá de que ninguna declaración, que se demuestre que ha sido hecha como resultado de tortura pueda ser invocada como prueba en ningún procedimiento, salvo en contra de una persona acusada de tortura como prueba de que se ha formulado la denuncia".

De otros instrumentos Internacionales que se observan como formando parte de nuestra constitución, entre los que podemos mencionar, por la cual se aprueba "La convención Americana de Derechos Humanos, aprobada por el Estado Colombiano por la ley 16 de 1972 en sus artículos 5, 7, 8, 9, 1011 y 25; La declaración Universal de los Derechos Humanos, artículos $3,5,6,8,11$ y 12 y el Convenio Europeo de Derechos Humanos, artículos 3,5,6,8, 13, se extractan e incorporan en nuestro ordenamiento penal, verdaderas garantías constitucionales que estructuran y delimitan la actividad probatoria, son génesis del respeto de derechos fundamentales, entre los que prevalecen: El derecho a la integridad personal y a la proscripción de la tortura; el derecho a un proceso justo; el derecho a la presunción de inocencia; el derecho a la intimidad, el principio de legalidad del delito y de la pena; el derecho a la exclusión de las declaraciones y confesiones involuntarias, el derecho a la exclusión de las pruebas obtenidas contrariando o violentando derechos fundamentales o garantías constitucionales. 
Adiciónese cómo, además de las normas constitucionales de las que hacen parte los tratados internacionales y el desarrollo legislativo en nuestros códigos penal y de procedimiento penal, las decisiones de los Tribunales Internacionales, estructuran y limitan la actividad probatoria, a más de ser criterios de necesaria observación, entre los destacamos, siguiendo a Urbano; (i) Tribunal Europeo de Derechos Humanos, en decisiones como "Irlanda del Norte contra Reyno Unido", del 18 de enero de 2018; "Assenor y otros contra Bulgaria", del 28 de octubre de 1998; "Resoluciones de inadmisión de Shannon contra el El Reino Unido de Gran Bretaña e Irlanda del Norte", del 22 de julio de 2003 y (ii) La Corte Interamericana de Derechos Humanos: "Caso Alan García contra Perú", 1994; Comité de Derechos Humanos, "Caso Bahamonde contra Guinea Ecuatorial", 1994; Comité de Derechos Humanos, "Caso Karttunen contra Finlandia" (Urbano, 2014)

Remémbrese, los instrumentos internacionales y sus desarrollos jurisprudenciales, determinan entre otros aspectos probatorios penales: i) La proscripción de ciertas técnicas de interrogatorio que en ciertas actuaciones penales constituyen tortura o tratos crueles; ii) la inadmisión de pruebas obtenidas mediante una actitud probatoria de la policía, a propósito del contemporáneo concepto del agente provocador; iii) la exclusión de elementos materiales probatorios, evidencia física o información obtenida mediante tortura, consagrada en la Convención contra la Tortura adoptada por la Asamblea General de las Naciones Unidas y por la Asamblea General de la Organización de Estados Americanos; iv) La exclusión de las pruebas ilegales $y, v)$ La inversión meramente excepcional de la carga de la prueba.
Conclúyase, destacando que la estructura probatoria al amparo de los derechos fundamentales propio de un sistema penal constitucionalizado y garante de los derechos humanos no puede ser inferior a obrar conforme a las decisiones del Comité de Derechos Humanos en el "Caso Kelly contra Jamaica, 1989"; la decisión del Tribunal Europeo de Derechos, en la sentencia Weh contra Australia, del 8 de abril de 2004; La regla de exclusión opera respecto de las declaraciones y elementos provenientes de tortura u otros tratos o penas crueles, inhumanos o degradantes o de toda presión fisica o psicológica directa o indirecta sobre el acusado de parte de las autoridades con miras a que se declare culpable; de las declaraciones autoinculpatorias de un acusado obtenidas mientras estaba detenido e incomunicado (Urbano, 2014).

\section{CONCLUSIONES}

A partir 1991, en la Constitución Política de Colombia, se admite la coexistencia de postulados del iuspositivismo y el iusnaturalismo, conforme a concepción teórica de Dworkin (1977) construidos sobre una teoría moral que no excluya ni el razonamiento moral ni el razonamiento filosófico y permita la positivización de principios que son una respuesta a la crisis del positivismo radical, teoría según la cual, todo concepto de derecho penal liberal que pretenda el respeto de los derechos humanos y los derechos fundamentales debe incorporarse en la Constitución positivada y desde esta impregnar el ordenamiento procesal penal.

Los valores abiertos de la constitución deben observarse como garantías a los derechos y no deben utilizarse para 
ampliar el poder punitivo del Estado, por el contrario, debe ser criterio de restricción, honrando el principio Pro Homine.

Se concluye de manera categórica que a partir de la promulgación de la Constitución Política de Colombia de 1991, nuestro Estado y nuestro ordenamiento penal interno, adquirieron avanzadas características de garantía de los derechos que permiten predicar el tránsito de un Estado de Derecho, de raigambre liberal a un Estado Social y Democrático de derechos, caracterizado por:

La existencia de un Estado Constitucional.

Un Estado Social de derecho garantista de los sujetos.

La honra del ordenamiento penal a los postulados garantistas de la constitución, regulando el poder punitivo del Estado como herramienta de convivencia pacífica de los asociados, pero con límites definidos en la actuación y respetuosos de la dignidad de las personas.

La inclusión de preceptos probatorios con valiosos contenidos tales como la reserva judicial de los derechos a la intimidad y a la libertad de locomoción, la regla de exclusión de la prueba ilícita y la exoneración del deber de declarar previstos en los artículos 15, 28, 29 y 33 de la norma superior.

Las normas precitadas como estructurantes constitucionales de la actividad probatoria en el derecho penal y procesal penal en Colombia, deben estar en todo en concordancia con instrumentos Internacionales que hacen parte de nuestra constitución, y que en manera alguna deben observarse como meras normas complementarias sino como preceptos de aplicación directa, entre los que podemos mencionar, convención Americana de Derechos Humanos, aprobada por el Estado Colombiano por la ley 16 de 1972 en sus artículos 5, 7, 8, 9, 1011 y 25; La declaración Universal de los Derechos Humanos, artículos 3,5,6,8,11 y 12 y el Convenio Europeo de Derechos Humanos, artículos 3,5,6,8, 13, se extractan e incorporan en nuestro ordenamiento penal, verdaderas garantías constitucionales que estructuran y delimitan la actividad probatoria, son génesis del respeto de derechos fundamentales, entre los que prevalecen: El derecho a la integridad personal y a la proscripción de la tortura; el derecho a un proceso justo; el derecho a la presunción de inocencia; el derecho a la intimidad, el principio de legalidad del delito y de la pena; el derecho a la exclusión de las declaraciones y confesiones involuntarias, el derecho a la exclusión de las pruebas obtenidas contrariando o violentando derechos fundamentales o garantías constitucionales. 


\section{BIBLIOGRAFÍA}

Armijo, G. (1997). Garantías constitucionales, prueba ilícita y la transición al nuevo proceso penal. San José de Costa Rica: Investigaciones jurídicas.

Asamblea general de las Naciones Unidas. (1948, 10 de diciembre). Declaración Universal de los Derechos Humanos. Resolución 217.

Bobbio, N (1982). El problema de la guerra y las vías de la paz. Barcelona: Gedisa.

Bonorino, P. y Peña, J. (2008). Filosofía del derecho (2 ed.). Bogotá, D.C., Colombia: Consejo Superior de la Judicatura, 2008.

Carrasquilla, J. (2014). Concepto y Límites del Derecho Penal. Bogotá, Colombia: Temis.

Código de Procedimiento Penal. (1 de septiembre de 2004). Artículo 23, ley 906 de 2004.

Congreso de Colombia (1972, 30 de diciembre). Ley 16 de 1972. Ley aprobatoria de tratado. En: Diario oficial No. 33780 (1973, 5 de febrero).

Congreso de Colombia (1986, 5 de diciembre). Ley 70 de 1986. En: Diario oficial No. 41013 (1993, 31 de agosto)

Constitución Política de Colombia de 1991. Título VII, Capítulo 4, Artículo 93.

Daza, A. (2015). Evidencia ilícita y cláusula de exclusión: límites de la policía de vigilancia en la prevención del delito y de la policía judicial en la investigación del mismo, en el estado social y democrático de derecho. Bogotá: Grupo Editorial Ibáñez. 
Dowrkin, R. (1977). Los Derechos en serio. Barcelona, España: Ariel.

Dowrkin. (1977). Los derechos en serio. Barcelona, Epaña: Ariel S.A.

Fernández, J. (2014). Concepto y Límites del Derecho Penal. Bogotá: Temis.

Ferrajoli, L. (2016). Derechos Fundamentales - Democracia Constitucional y Garantismo. Bogotá: Orión Editores S.A.S.

Gómez, O. (2010). El derecho penal en un Estado Democrático y de derecho. En: Perspectiva, Dossier edición 24.

Kelsen, H. (2008). La doctrina del derecho natural y el positivismo jurídico. Academia. Revista sobre enseñanza del derecho (12), 183-198. Recuperado 02 de junio de 2019, de la fuente: http://www.derecho. uba.ar/publicaciones/rev_academia/ revistas/12/la-doctrina-del-derecho-natural-y-el-positivismo-juridico.pdf

Pérez, D. (2013). De Derechos: humanos, naturales, fundamentales y de gentes. Universidad Andaluza Inca Garcilaso. Recuperado de: http://www.eumed.net/libros-gratis/2013a/1323/1323.pdf.

Upriminy, R., Uprimny, M. y Parra, O. (2008). Derechos humanos y derecho Internacional Humanitario. Bogotá, D.C., Colombia: Escuela judicial "Rodrigo Lara Bonilla".

Urbano, J. (2014). La Nueva Estructura Probatoria del Proceso Penal. Bogotá, Colombia: Ediciones Nueva Jurídica.

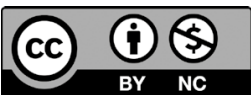

Esta obra está bajo una licencia de Creative Commons

Reconocimiento-NoComercial 4.0 Internacional 